\title{
Iritis, glaucoma and corneal decompensation associated with BrightOcular cosmetic iris implant
}

\author{
Ahmad M Mansour, ${ }^{1,2}$ Iqbal Ike K Ahmed, ${ }^{3}$ Brennan Eadie, $^{3}$ Elias Chelala, ${ }^{4}$ \\ Joanna S Saade, ${ }^{1}$ Stephen G Slade, ${ }^{5}$ Ali A Mearza, ${ }^{6}$ Dipak Parmar, ${ }^{7}$ \\ Marwan Ghabra, ${ }^{7}$ Sheila Luk, ${ }^{8}$ Alla Kelly, ${ }^{9}$ Stephen C Kaufman ${ }^{9,10}$
}

For numbered affiliations see end of article.

\section{Correspondence to} Iqbal Ike K Ahmed,

Department of Ophthalmology, University of Toronto, Toronto, Ontario, Canada; ikeahmed@ mac.com

Received 15 June 2015 Revised 13 November 2015 Accepted 28 November 2015 Published Online First 30 December 2015

\section{CrossMark}

To cite: Mansour AM,
Ahmed IIK, Eadie B, et al. Br
J Ophthalmol
2016;100:1098-1101.

To cite: Mansour AM, J Ophthalmol

2016;100:1098-1101.

\section{ABSTRACT}

Purpose NewColorlis cosmetic iris implants have a record of high ocular morbidity and are no longer in use. Newer generation of iris implants, BrightOcular, have patented posterior grooves in order to decrease iris touch and facilitate aqueous flow around the implant.

However, little is known about their safety despite their implantations in 10 countries.

Methods Collaborative case series of patients who had bilateral implantation of cosmetic iris implants solely for cosmetic reasons.

Results 12 cases were collected being distributed as Caucasian (10) and Asian (2), women (11) and man (1) and with a mean age of 32 years. Ocular manifestations were present in 11 subjects and included anterior uveitis (10 of $12 ; 83.3 \%)$, glaucoma (7 of $12 ; 58.3 \%$ ) and corneal decompensation (6 of 12; $50 \%$ ). Visual acuity was normal in seven, decreased in five with two having visual recovery following explantation of the implant. Glaucoma could not be controlled medically in two patients.

Conclusions Cosmetic iris implants carry the risk of ocular damage when implanted in the anterior chamber of normal phakic eyes.

\section{INTRODUCTION}

Iris implants were initially designed to treat aniridia, ocular albinism and iris coloboma. ${ }^{1-16}$ Such implants were relatively safe when they were placed in the sulcus or in the lens bag and were custom made $^{17}$ (Morcher (Stuttgart, Germany), Ophtec (Groningen, Netherlands) and Humanoptics (Erlangen, Germany)). Iris implant to permanently alter iris colour in healthy eyes constitutes an attractive concept for both ophthalmologists and patients who seek a cosmetic treatment. The first cosmetic iris implant NewColorIris (Kahn Medical Devices, Panama City, Panama) was patented in 2006 (US patent 2006 \#7025781 2B) and was performed in Panama with interested subjects travelling to have their surgery done. ${ }^{1-13}$ As of 2010, $>700$ procedures were performed. The implant consisted of one size silicone plate having a diameter of $15 \mathrm{~mm}$, a thickness of $0.16 \mathrm{~mm}$, a pupillary margin of $3.5 \mathrm{~mm}$ and a total of six anchoring hinges. However, this surgery was associated with serious vision threatening complications requiring multiple intraocular surgeries. ${ }^{1-13}$

A newer generation cosmetic iris implant, BrightOcular (Stellar Devices, New York, USA), has patented posterior grooves that allow better flow of aqueous and minimise iris chaffing (US patent 2012 \#8197540). The changes are: custom made with variable length. (The overall diameter $11.5-13.5 \mathrm{~mm}$; thickness vary from 0.3 to 0.5 from sectorial posterior grooves; five rounded triangular edges $0.12-0.14 \mathrm{~mm}$ thick and 0.8 $1 \mathrm{~mm}$ long.) The official company site (http://www. brightocular.com) and associated surgical videos have publicised the safety of the new device by mentioning that the patent for the implant is approved and that the silicone material used is approved. The device does not have US Food and Drug Administration (FDA) approval and there is no data in the literature to substantiate its safety. ${ }^{14} 15$ Given the well-known ocular complications from NewColorIris implants, ${ }^{1-13}$ doubt is raised about the safety profile of this new BrightOcular device. We present a series of patients who had bilateral implantation of coloured iris implants solely for cosmetic reasons and presented thereafter with various ocular morbidities.

\section{METHODS}

We collected cases of BrightOcular cosmetic iris implants contacting authors who previously published about the broader subject of cosmetic iris implants in meetings (European Society of Cataract and Refractive Surgery and American Society of Cataract and Refractive Surgery), videos or PDF in Google or in PubMed. A large majority of contributors dealt with NewColorIris cases only and were excluded. Two sites (Moorfields Eye Hospital, London, UK and Mayo Clinic, Minnesota, USA) mentioned that they have their own series and they intend to submit their work for publication. Surgeons associated with the official BrightOcular site were also contacted by email. BrightOcular cosmetic iris implants were differentiated from NewColorIris cosmetic iris implants by: colour flecks on the anterior surface (in most versions of BrightOcular) (figures 1A, B and 2), five spiky protrusions (figure 3) (vs six rounded protrusions for NewColorIris figure 4) and 10 posterior grooves (figures 3 and 5).

\section{RESULTS}

Twelve cases had bilateral implants of BrightOcular performed in the following countries: Lebanon (33.3\%) and Tunisia (33.3\%) each having four patients and Jordan (16.7\%) and Turkey (16.7\%) each having two patients (table 1). Three cases were previously presented in part as surgical videos or PubMed. ${ }^{14}{ }^{15}$ Each centre supplied a single case except four cases from University of Toronto and two cases (sisters) from 




B

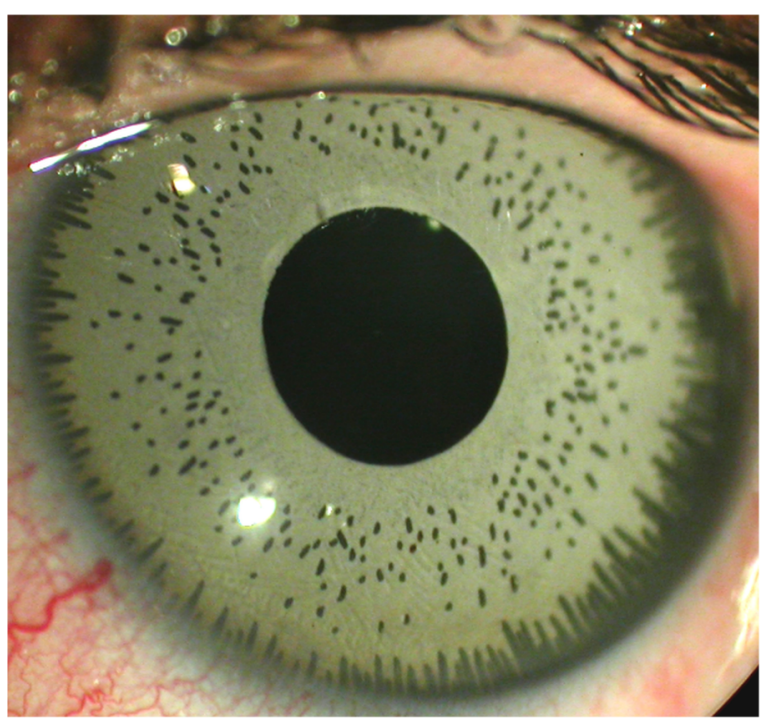

Figure 1 ( $A$, right eye) and ( $B$, left eye)-anterior segment of airline hostess (case 2) showing a cosmetic iris implant presenting with uncontrolled uveitis since the implantation and after three subtenon injections of corticosteroids along with topical corticosteroid and non-steroidal anti-inflammatory drops. Subconjunctival haemorrhage in the right eye happened after a most recent subconjunctival injection of corticosteroid.

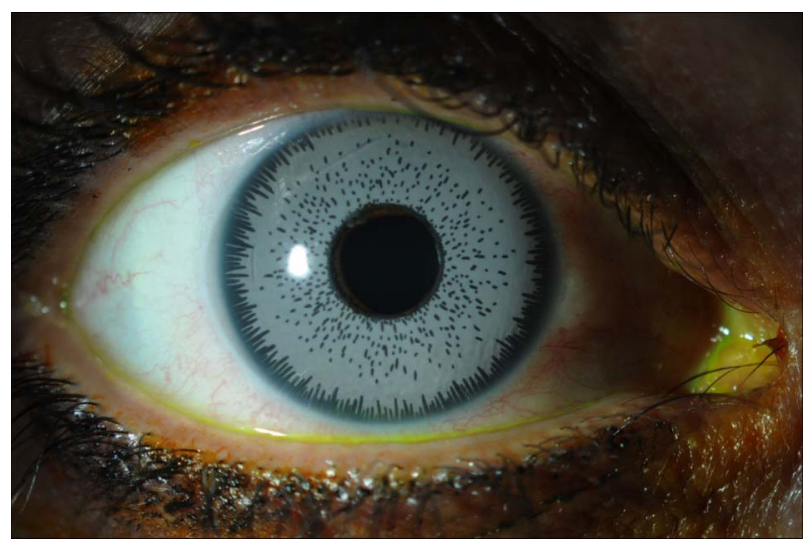

Figure 2 Slit lamp appearance before explantation in case 1. Colour flecks are noted on the anterior surface of the BrightOcular cosmetic iris implant.

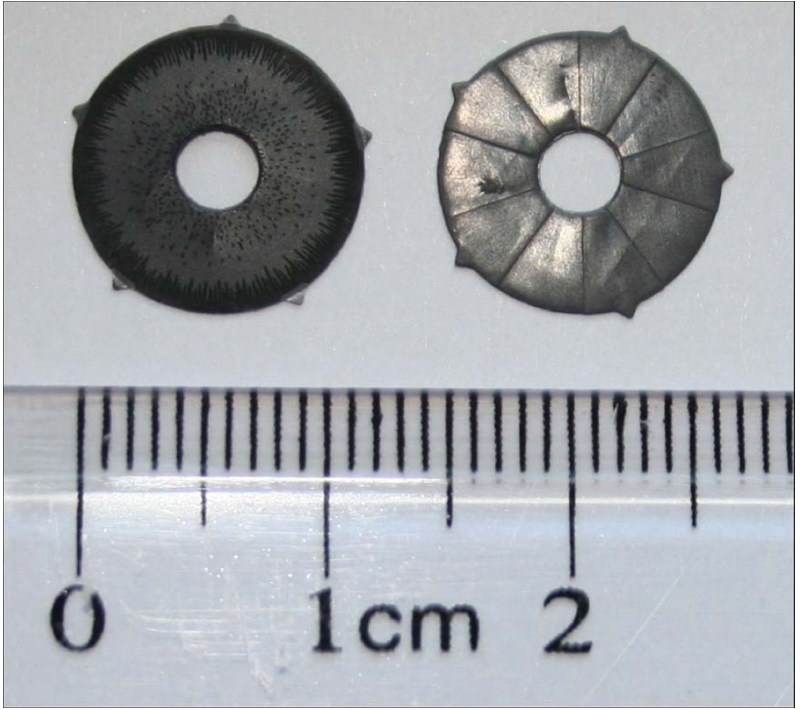

Figure 3 Explanted BrightOcular cosmetic iris implant in case 1. Colour flecks on the anterior surface, five spiky protrusions and 10 posterior radial grooves.

Hotel Dieu de France. The majority of subjects were Caucasian $(83.3 \%)$ and were women $(91.7 \%)$ with a mean age of 32 years (range 24-40). Ocular morbidity included uveitis in 10 patients $(83.3 \%$ ) (figure $1 \mathrm{~A}, \mathrm{~B}$ ), glaucoma in seven patients $(58.3 \%)$ and corneal decompensation or oedema in six patients $(50 \%)$. Vision was normal in seven patients $(58.3 \%)$ and was decreased in five patients $(41.7 \%)$ but improved after explantation in two patients (25\%). Uveitis recurred in one patient 3 months after explantation. Glaucoma persisted in one case (case 1) from extensive peripheral anterior synechiae. The absence of peripheral iridotomy was noted in two cases. Corneal decompensation was reversible in six cases after control of uveitis, lowering of intraocular pressure and explant surgery. There was iris apposition of the implant with some form of iris tuck in the angle in three patients (cases 2, 5 and 6) by anterior segment optical coherence tomography. Patchy loss of anterior stromal pigment along the mid-periphery was noted in one patient after explant (case 5). Sector iris atrophy with holes was also noted at the site of the implant hinges (case 3) (figure 6). Explantation was performed in eight patients within 2 years of the implantation. One patient refused to remove the implant because her positive cosmetic results outweighed her iritis symptoms while another patient expressed the desire to remove the implant in her home

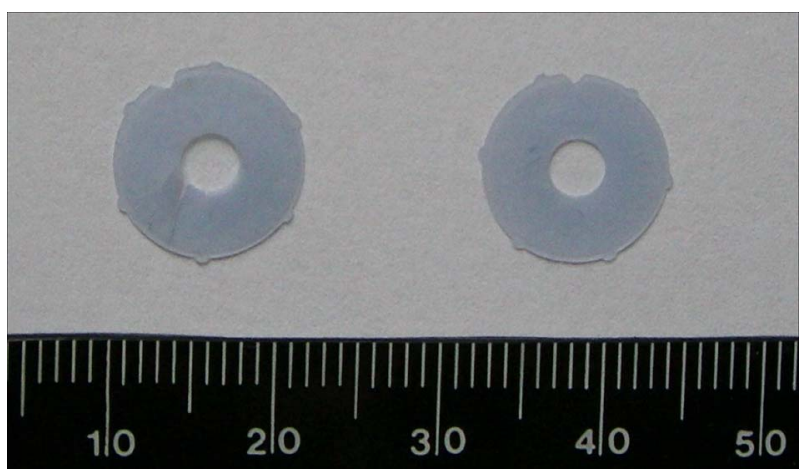

Figure 4 Explanted NewColorlris cosmetic iris implants showing six rounded protrusions. 




Figure 5 Case 5 . Note the posterior grooves in an explanted BrightOcular cosmetic iris implant.

country. Two sisters (cases 7 and 8) refused to have their implant removed on the same day that the implant was done. Intraocular pressure could not be controlled in these two

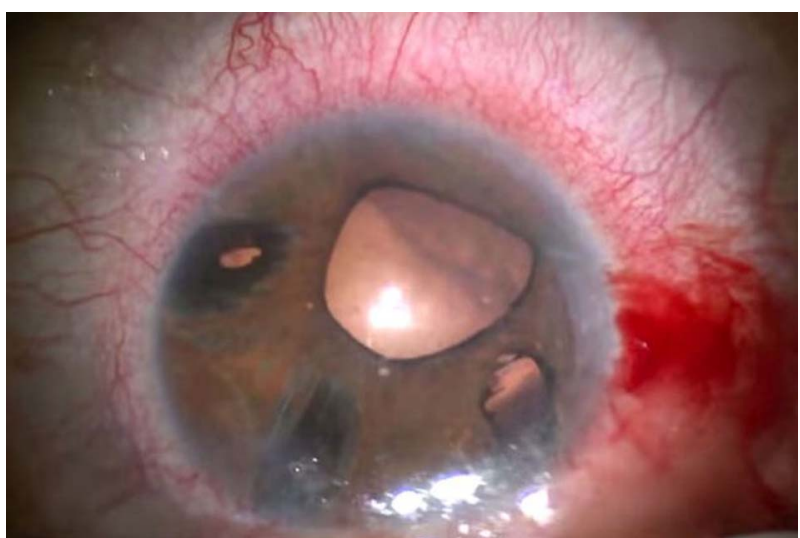

Figure 6 Intraoperative photograph of the iris defects at the site of implant hinges immediately following explantation (case 3).

sisters despite maximal medical therapy. A single patient had no ocular signs and symptoms (case 10) but requested prophylactic removal of the implants after learning of the potential side effects in the media.

Table 1 Clinical summary of 12 patients with BrightOcular iris implant

\begin{tabular}{|c|c|c|c|c|c|c|c|c|c|}
\hline $\begin{array}{l}\text { Case } \\
\text { number-country } \\
\text { of implantation }\end{array}$ & Age & Gender & Race & Uveitis & Glaucoma & $\begin{array}{l}\text { Corneal } \\
\text { decompensation }\end{array}$ & $\begin{array}{l}\text { Explantation } \\
\text { months after } \\
\text { implant }\end{array}$ & $\begin{array}{l}\text { Subsequent } \\
\text { surgeries }\end{array}$ & Vision \\
\hline 1-Tunisia & 40 & $\mathrm{~F}$ & $\mathrm{C}$ & $\begin{array}{l}\text { Yes OU (resolved } \\
\text { after explantation) }\end{array}$ & $\begin{array}{l}\text { Yes OD } 42 \mathrm{~mm} \mathrm{Hg} \text {, } \\
\text { OS } 10 \mathrm{~mm} \mathrm{Hg} \text { on } \mathrm{Rx} \text {; } \\
\text { peripheral anterior } \\
\text { synechiae } 300^{\circ} \mathrm{OD} \\
\text { and } 270^{\circ} \mathrm{OS}\end{array}$ & $\begin{array}{l}\text { Yes OD: endothelial cell } \\
\text { count } 1197 / \mathrm{mm}^{2} \text { OD, } \\
2372 / \mathrm{mm}^{2} \text { OS }\end{array}$ & $\begin{array}{l}\text { Yes after } \\
5 \text { months }\end{array}$ & $\begin{array}{l}\text { Planned } \\
\text { filtration OD }\end{array}$ & $\begin{array}{l}\text { Initial } 6 / 24 \text { OD } \\
6 / 6 \text { OS; final } 6 / 6 \\
\text { oU }\end{array}$ \\
\hline 2-Lebanon & 39 & $\mathrm{~F}$ & C & $\begin{array}{l}\text { Yes OU uncontrolled } \\
\text { despite three monthly } \\
\text { subtenon } \\
\text { corticosteroid } \\
\text { injections }\end{array}$ & No & No & $\begin{array}{l}\text { No (patient } \\
\text { refused) }\end{array}$ & No & $6 / 6$ OU \\
\hline 3-Turkey & 25 & $\mathrm{~F}$ & C & Yes OU & Yes OU $35 \mathrm{~mm} \mathrm{Hg}$ & $\begin{array}{l}\text { Yes OU with corneal } \\
\text { neovascularisation OU }\end{array}$ & $\begin{array}{l}\text { Yes after } \\
12 \text { months }\end{array}$ & No & $\begin{array}{l}6 / 30 \text { OU } \\
\text { normalised } \\
\text { subsequently } \\
\text { OU }\end{array}$ \\
\hline 4-Tunisia & 24 & $M$ & $C$ & $\begin{array}{l}\text { Yes (started } 6 \text { months } \\
\text { after implantation; } \\
\text { recurred } 2 \text { months } \\
\text { after explantation) }\end{array}$ & No & No & $\begin{array}{l}\text { Yes after } \\
12 \text { months }\end{array}$ & No & $6 / 6$ OU \\
\hline 5-Lebanon & 35 & $\mathrm{~F}$ & $C$ & Yes OU & No & Yes OD & $\begin{array}{l}\text { Yes after } \\
1 \text { month }\end{array}$ & No & $6 / 6$ OU \\
\hline 6-Tunisia & 38 & $\mathrm{~F}$ & C & No & & No & $\begin{array}{l}\text { No (patient } \\
\text { advised) }\end{array}$ & No & $6 / 6$ OU \\
\hline 7-Lebanon & 25 & $\mathrm{~F}$ & $C$ & Yes OU & $\begin{array}{l}\text { Yes } 55 \mathrm{~mm} \mathrm{Hg} \text { OD } \\
62 \mathrm{~mm} \mathrm{Hg} \mathrm{OS} \mathrm{(not} \\
\text { respond to medical } \\
\text { therapy; no PI) }\end{array}$ & Yes & $\begin{array}{l}\text { No (patient } \\
\text { advised) }\end{array}$ & No & $\begin{array}{l}\text { CF } 2 \text { m OD; } 20 / \\
400 \text { OS }\end{array}$ \\
\hline 8-Lebanon & 26 & $\mathrm{~F}$ & $C$ & Yes OU & $\begin{array}{l}\text { Yes } 48 \mathrm{~mm} \mathrm{Hg} \text { OD } \\
50 \mathrm{~mm} \mathrm{Hg} \mathrm{OS} \mathrm{(not} \\
\text { respond to medical } \\
\text { therapy; no PI) }\end{array}$ & Yes & $\begin{array}{l}\text { No (patient } \\
\text { advised) }\end{array}$ & No & $\begin{array}{l}\text { CF } 4 \text { m OD; } 20 / \\
400 \text { OS }\end{array}$ \\
\hline 9-Jordan & 32 & $\mathrm{~F}$ & C & Yes OU & Yes & Yes & $\begin{array}{l}\text { Yes after } \\
24 \text { months }\end{array}$ & No & $6 / 12$ OD; 6/6 OS \\
\hline 10-Jordan & 25 & $\mathrm{~F}$ & $C$ & No & No & No & $\begin{array}{l}\text { Yes after } \\
18 \text { months }\end{array}$ & No & $6 / 6$ OU \\
\hline 11-Turkey & 38 & $\mathrm{~F}$ & A & Yes OU & No & No & $\begin{array}{l}\text { Yes after } \\
12 \text { months }\end{array}$ & No & $6 / 6$ OU \\
\hline 12-Tunisia & 33 & $\mathrm{~F}$ & A & Yes OU & Yes & No & $\begin{array}{l}\text { Yes after } \\
12 \text { months }\end{array}$ & No & $6 / 6$ OU \\
\hline
\end{tabular}

Cases 5 and 6 were partly mentioned previously. ${ }^{14}{ }^{15}$

C, Caucasian; CF, counting fingers; F, female; M, male; OD, right eye; OS, left eye; OU, bilateral; PI, peripheral iridotomy; $R x$, therapy. 


\section{DISCUSSION}

Cosmetic implants, of this type, to change eye colour were first developed by a surgeon in Panama but were discontinued due to significant complications, some leading to permanent ocular damage that occurred in these patients. ${ }^{1-13}$ Since then, a newer type of implant found its way to 10 countries: Turkey, Tunisia, India, China, Lebanon, Jordan, Syria, Mexico, Costa Rica and Albania. Cosmetic iris implants are not approved for use in the USA, Europe and UK. ${ }^{14}{ }^{15}$ This ocular implant alters iris colour for medical and cosmetic purposes and is made of an inert, nontoxic, foldable material (US patent 2012 \#8197540). It is an annular non-planar structure that covers the iris and extends approximately to the iridocorneal angle. Two different kinds of arc sections of a non-uniform thickness make up the structure: passage arc sections and support are sections. The passage arc sections purport to permit humour aqueous flow under the implant. The support arc sections make contact with the iris and claim to provide the necessary support for the passage arc sections. Five triangular, peripheral tips extend from the support arc sections and are configured to hold the implant in place by engaging the eye at the iridocorneal angle.

Our reported cases document the occurrence of anterior segment damage (uveitis, glaucoma and corneal decompensation), secondary to BrightOcular implantation. The BrightOcular may pose less risk than the NewColorIris device that has additional intraocular positioning and surface characteristics problems. Inappropriately sized anterior chamber implants deleteriously affect corneal endothelial cell counts and angle structures. Surface irregularities contributed to uveitis and trabecular meshwork damage as shown by scanning electron microscopy. ${ }^{4}$ BrightOcular with the patented grooves may have partially corrected some of the problems inherent with NewColorIris. Previous designs of iris implants were accompanied by more severe complications with irreversible blindness and subsequent need for multiple interventions (Descemet's stripping automated endothelial keratoplasty, corneal transplantation, trabeculectomy, valve placement, cataract removal) (US patent 2012 \#8197540). ${ }^{14} 15$

The mechanisms of glaucoma or rise in intraocular pressure include: chronic anterior segment inflammation; pigment dispersion from chafing of the iris, compression of the trabecular meshwork with peripheral anterior synechiae; angle closure glaucoma; pupillary block due to lens implantation without iridotomies being performed and steroid-induced ocular hypertension from therapy used to control anterior uveitis. Mechanisms of uveitis include chafing of the hinges with the iris periphery, chafing of the diaphragm with the iris body, surface irregularities of the implant causing iris irritation. ${ }^{4}$ Corneal endothelial loss results in corneal oedema and permanent visual loss from glaucoma, iritis and implant-corneal touch at the periphery. Permanent pupillary abnormalities (sectorial atrophy) can persist after explantation and result from erosion or melt of the peripheral iris by the hinges. Uveitis and glaucoma can recur or persist after explantation. Due to the high likelihood of postexplantation sequelae in these patients, they should receive long-term follow-up. Each complication needs to be addressed. However, the first step is explantation by cutting the implant into pieces ${ }^{16}$ or removing it as one piece. ${ }^{6}$

The current report has many drawbacks: retrospective small series, different workup for each case, short follow-up (most lived overseas) and referral bias. In conclusion, cosmetic iris implants carry a high risk of irreversible visual loss (most pronounced in the literature with NewColorIris and in the current series with BrightOcular) that should be highlighted for subjects seeking change in iris colour.

\section{Author affiliations}

${ }^{1}$ Department of Ophthalmology, American University of Beirut, Beirut, Lebanon ${ }^{2}$ Department of Ophthalmology, Rafic Hariri University Hospital, Beirut, Lebanon ${ }^{3}$ Department of Ophthalmology, University of Toronto, Toronto, Ontario, Canada ${ }^{4}$ Department of Ophthalmology, Hotel Dieu de France, Beirut, Lebanon

${ }^{5}$ The Laser Center, Houston, Texas, USA

${ }^{6}$ Department of Ophthalmology, Imperial College, London, UK

${ }^{7}$ Department of Ophthalmology, Whipps Cross University Hospital, London, UK

${ }^{8}$ Department of Ophthalmology, Western Eye Hospital, London, UK

${ }^{9}$ Department of Ophthalmology and Visual Neurosciences, University of Minnesota,

Minneapolis, Minnesota, USA

${ }^{10}$ Department of Ophthalmology, State University of New York Downstate, Brooklyn, New York, USA

\section{Twitter Follow Ali Mearza at @alimearza}

Contributors AMM was involved in the design and planning of the study, participated in data collection, developed the analytical strategy for this paper, undertook the data analyses presented here and wrote the paper. IIKA was involved in the planning and data collection with extensive review of the paper. BE was involved in data collection and paper review. EC was involved in data collection and review of the paper. JSS was involved in planning of the study and commented on the paper. SGS, AAM, DP, MG, SL and AK undertook data collection, some data analyses and commented on the paper. SCK was involved in data collection and commented extensively on the paper.

Competing interests None declared.

Patient consent Obtained.

Ethics approval Ethical approval was given by the Institutional Review Board at Rafic Hariri University Hospital, Beirut, Lebanon.

Provenance and peer review Not commissioned; externally peer reviewed.

\section{REFERENCES}

1 Hoguet A, Ritterband D, Koplin R, et al. Serious ocular complications of cosmetic iris implants in 14 eyes. J Cataract Refract Surg 2012;38:387-93.

2 McCall D, Hamilton A, Grigg J, et al. Severe glaucoma and vision loss due to cosmetic iris implants. Med J Aust 2015;202:181.

3 Arthur SN, Wright MM, Kramarevsky N, et al. Uveitis-glaucoma-hyphema syndrome and corneal decompensation in association with cosmetic iris implants. Am J Ophthalmol 2009;148:790-3.

4 Castanera F, Fuentes-Páez G, Ten P, et al. Scanning electron microscopy of explanted cosmetic iris implants. Clin Experiment Ophthalmol 2010;38:648-51.

5 Mamalis N. Cosmetic iris implants. J Cataract Refract Surg 2012;38:383.

6 Hull S, Jayaram H, Mearza AA. Complications and management of cosmetic anterior chamber iris implants. Cont Lens Anterior Eye 2010;33:235-8.

7 MacDonald L. Cosmetic iris implants: is vanity worth losing your vision? Optometry J Am Optometric Assoc 2010;81:281-2.

8 Thiagalingam S, Tarongoy P, Hamrah P, et al. Complications of cosmetic iris implants. J Cataract Refract Surg 2008;34:1222-4.

9 Anderson JE, Grippo TM, Sbeity Z, et al. Serious complications of cosmetic NewColorlris implantation. Acta Ophthalmol 2010;88:700-4.

10 Sikder S, Davis SW, Patel VP, et al. Complications and management of NewColorlris implantation in phakic eyes. J Ref Surg 2011;27:239-40.

11 George MK, Tsai JC, Loewen NA. Bilateral irreversible severe vision loss from cosmetic iris implants. Am J Ophthalmol 2011;151:872-5.

12 Veldman PB, Behlau I, Soriano $\mathrm{E}$, et al. Two cases of cosmetic iris implant explantation secondary to uveitis, glaucoma, and corneal decompensation. Arch Ophthalmol 2012;130:787-9.

13 Garcia-Pous M, Udaondo P, Garcia-Delpech S, et al. Acute endothelial failure after cosmetic iris implants (Newlris@). Clin Ophthalmol 2011;5:721-3.

14 Kelly A, Kaufman SC. Corneal endothelial cell loss and iritis associated with a new cosmetic iris implant. JAMA Ophthalmol 2015;133:723-4.

15 Luk S, Spiteri A, Muthusamy K, et al. Cosmetic iris implantation complicated by secondary angle closure. Cont Lens Anterior Eye 2015;38:142-3.

16 Arjmand P, Gooi P, Ahmed II. Surgical technique for explantation of cosmetic anterior chamber iris implants. J Cataract Refract Surg 2015;41:18-22.

17 Price MO, Price FW Jr, Chang DF, et al. Ophtec iris reconstruction lens United States clinical trial phase I. Ophthalmology 2004;111:1847-52. 